\title{
The influence of gut micro-organisms on the metabolism of drugs and food additives
}

\author{
By R. WALKer, Department of Biochemistry, University of Surrey, Guildford
}

\section{Introduction}

Nutritionists have long been aware of the importance of the gut microflora in the metabolism of nutrients but only recently has their importance been recognized in the metabolism of some endogenous compounds, such as bile salts (Gustafsson, 1967; Dickenson, Gustafsson \& Norman, 1971), drugs, food additives, and other anutrients. This is surprising in view of the early interest in intestinal metabolism (the conversion of tryptophan to indole by the gut flora was recorded last century). However, due to Scheline (1968a) and Williams ( 1970 ), the metabolic potential of the intestine is now recognized as comparable with that of the liver.

The range of reactions performed by the gut microflora is wide and Drasar, Hill \& Williams (1970) have asserted that there are some bacteria which are able to metabolize any organic molecule. Indeed, Murrells (1969) isolated organisms from rat caecums which were able to utilize some azo food colours as sole nitrogen or carbon sources.

In this paper, the types of reactions which occur and their significance in the pharmacology and toxicology of drugs and food additives will be briefly surveyed.

\section{Transformations of anutrients by intestinal microflora}

The types of molecular transformations resulting from the activity of intestinal microflora have been reviewed by Scheline (1968a, 1971) and are shown in Table $\mathrm{I}$.

It can be seen that these reactions are mainly hydrolytic or other degradations and reductions. This contrasts with hepatic metabolism of anutrients where oxidations and syntheses (e.g. conjugations) predominate. This gives rise to many possibilities of competition between mammalian and microbial metabolism, sequential reactions and enterohepatic circulation, the consequences of which are reviewed below.

\section{Lethal synthesis}

\section{Consequences of intestinal metabolism of anutrients}

In some instances, metabolites produced by the intestinal microflora are more toxic than the parent compound. This is true of many phenolic aldehydes and carboxylic acids which occur naturally in the diet and are also used as food flavours, for example vanillin. Scheline $(1968 b, 1972)$ has demonstrated that these may be $32(2) 3$ 
Table 1. Transformations of anutrient compounds by intestinal microflora

I. Hydrolysis of :

(a) Glucuronides

(b) Esters

(c) Amides

(d) Ethereal sulphates

(e) Sulphamates

(f) Glycosides

2. Reduction of :

3. Degradation by :

4. Synthesis by:

5. Miscellaneous :

(d) Carbonyl compounds

(f) Arsonic acids

(a) Decarboxylation

(c) Deamination

(d) Dehalogenation

(a) Esterification

(b) Acetylation Aromatization

(a) Carbon-carbon double bonds

(b) Nitro- and azo-compounds

(c) $N$-oxides, $N$-hydroxy compounds

(e) Alcohols, phenols (dehydroxylations)

(b) Dealkylation ( $O$ - and $N$-alkyl)

(c) Formation of nitrosamines

reduced or decarboxylated to more toxic phenols. The significance of this at normal dietary concentrations is debatable but there are other examples of the production of toxic metabolites of considerable interest.

In studies of the toxicity of Brown FK, a permitted food colour, it was found that, unusually, this dye was more toxic on repeated oral administration than when given intraperitoneally to rats (Grasso, Gaunt, Hall, Golberg \& Batstone, r968). In related studies (Fore, Walker \& Golberg, I967; Walker, Grasso \& Gaunt, 1970) it was demonstrated that the toxicity was due to two polyamino compounds resulting from reduction of two components of Brown FK in the gut. After intraperitoneal administration the dyes were largely excreted in the urine unchanged. This illustrates differences in the toxicity of a compound administered by different methods resulting from intestinal metabolism.

Perhaps a more dramatic example of lethal synthesis is shown by amygdalin in mice (Williams, I970) where the oral $\mathrm{LD}_{50}$ (dose which is lethal to $50 \%$ of the mouse population) is $300 \mathrm{mg} / \mathrm{kg}$ compared with an intraperitoneal $L_{50}$ of $5000 \mathrm{mg} / \mathrm{kg}$. This is due to hydrolysis of this glycoside by the gut flora to yield the cyanogenetic benzaldehyde, cyanohydrin.

Recently, attention has been focused on the possibility that carcinogenic nitrosamines may be produced in vivo from nitrites and secondary amines. Nitrites are used as food preservatives and may be produced by microbial reduction of nitrate; secondary amines may be present in the diet and drugs or may be products of microbial metabolism. Hawksworth \& Hill (197I) have demonstrated that the intestinal microflora can catalyse the synthesis of nitrosamines at neutral $\mathrm{pH}$ and that some strains of intestinal organism can also reduce nitrate to nitrite. The significance of these observations for man is doubtful since nitrate would probably be absorbed before reaching the heavily populated regions of the gut but some species used in toxicity testing are coprophagous and may carry large numbers of micro-organisms in the stomach and small intestine. 
Detoxication

Examples of detoxication by gut microflora are not numerous since hydrolysis of biliary conjugates frequently results in the liberation of more toxic compounds. One possible exception to this generalization is $N$-hydroxy- $N$-2-fluorenylacetamide which is conjugated with glucuronic acid and excreted in the bile. This conjugate is more carcinogenic than the $N$-hydroxy precursor which in turn is more carcinogenic than the unhydroxylated $N$-2-fluorenylacetamide (Miller \& Miller, i967). The gut flora, by progressively hydrolysing the conjugate and dehydroxylating the $N$-hydroxy compound, produce compounds of lower carcinogenicity (Grantham, Horton, Weisburger \& Weisburger, 1970).

Reduction of azo compounds may lead to detoxication in some instances, for example Butter Yellow, where the carcinogenicity does not result from the amines produced on reduction (Kirby, I945). Dietary riboflavin moderates the carcinogenicity of Butter Yellow (Miller \& Miller, 1953) and it also stimulates azoreductase activity in rat caecal contents (Williams, Grantham, Yamamoto \& Weisburger, 1970). The specific activity of the microbial azoreductase is higher than that of the liver so intestinal metabolism may represent a significant detoxication.

\section{Enterohepatic circulation}

Many drugs and food additives are conjugated with glucuronic, acetic or sulphuric acids and excreted in the bile. Polar conjugates are poorly absorbed from the gut but are exposed there to the hydrolytic activity or the microflora. After hydrolysis the parent compound may be absorbed into the portal system thus setting up an enterohepatic cycle (Williams, Millburn \& Smith, 1965) delaying excretion and prolonging pharmacological activity. A classic example is stilboestrol (Clark, Fischer, Millburn, Smith \& Williams, 1968).

\section{Species differences}

These may arise from differences in gut structure and motility as well as from the quantitative and qualitative differences in composition and distribution of the flora reviewed by Drasar et al. (1970).

The most extensive study yet reported is that on the aromatization of quinic acid by twenty-two species including man (Adamson, Bridges, Evans \& Williams, 1970). Aromatization varied from zero in dog, cat and mouse to $60 \%$ in man and striking differences existed between Old World and New World monkeys.

Differences such as this in the metabolism of drugs and food additives may be of importance in extrapolating from animals to man in pharmacological or toxicological studies. Thus in the work on Brown FK previously mentioned species differences in the oral toxicity have been shown probably to be due to differences in production and subsequent absorption of toxic metabolites. Similarly, comparative studies on the metabolism of the food colour Orange $G$ have shown that the rat and man excrete only traces of unreduced dye together with substantial amounts of aminophenols, free and conjugated, in the urine. Conversely, the ferret excretes substantial amounts of unreduced dye in the faeces together with some aniline ( R. Walker, I. F. Gaunt 
\& P. Grasso, unpublished results). These differences appear to be due to differences in gut structure and motility as ferret intestinal flora were capable of reducing Orange $\mathrm{G}$ in vitro.

\section{Strain and interindividual differences}

These may be due to environmental factors so that differences in the composition of the gut flora, and hence in intestinal metabolism, might be expected between conventional, specific pathogen-free and axenic animals of the same species. A striking example of this is the metabolism and toxicity of cycasin (methylazoxymethylglycoside), which is found in cycad nuts. Cycasin is a potent carcinogen when given orally to conventional rats but not when given intraperitoneally; it is not carcinogenic on oral administration to axenic rats (Spatz, Smith, McDaniel \& Laqueur, I967). In conventional animals the inactive glycoside is hydrolysed to carcinogenic methylazoxymethanol but this metabolite is not produced in the gut of axenic animals.

Strain and interindividual differences also are observed in the intestinal metabolism of cyclamate to cyclohexylamine in man and rat. For example Kojima \& Ichibagase (I966) found all their subjects to be converters, whereas Leahy, Wakefield \& Taylor $(1967 a, b)$ found only a minority could convert cyclamate to cyclohexylamine. An interesting feature of the metabolism of cyclamate is that it is inducible (vide infra).

\section{Changes in pattern of intestinal metabolism}

Adaptation. Renwick \& Williams ( 1969 ) found that chronic dosing of rats with cyclamate led to an increase in the number of converters and in the amount of cyclamate converted to cyclohexylamine. This adaptation to dietary cycalamate has also been observed in man and is reversible. The micro-organisms responsible for production of cyclohexylamine have been identified (Drasar, Renwick \& Williams, I971) and different genera are involved in rabbit, rat and man.

Adaptation may result from selection pressures or from enzyme induction, and the differences observed between Japanese and Europeans cited above probably arise from dietary differences resulting in qualitatively different intestinal populations.

Dietary modification. The extent to which diet influences intestinal metabolism of anutrients has received little attention although it is known that there are dramatic changes in gut flora on weaning and there are enormous differences between herbivores and carnivores. One of the few reported examples of diet modifying intestinal metabolism is the effect of dietary riboflavin on the metabolism of Butter Yellow mentioned earlier.

Drugs. Drugs may modify their own metabolism or the metabolism of other compounds by their action on the gut flora. Indeed, pretreatment with antibiotics is frequently used to suppress microbial metabolism to distinguish this from metabolism in the tissues. Thus Clark et al. (1968) were able to demonstrate that oral antibiotics suppressed the hydrolysis of stilboestrol monoglucuronide which had the effect of reducing the rate of absorption of stilboestrol to one-fiftieth of the rate in untreated animals. 
It is clear that the practice of polypharmacy including large doses of oral antibiotics might profoundly affect drug metabolism and pharmacological activity.

\section{Differences in pharmacological activity}

The classic example of intestinal metabolism increasing the activity of a drug is Prontosil and Neoprontosil. The antibacterial activity of these compounds is due to the reduction product, sulphanilamide, and Gingell, Bridges \& Williams (1969) showed that a significant amount of the reduction of Prontosil and most of the reduction of Neoprontosil occured in the gut.

\section{Conclusions}

It has been shown that the metabolism of drugs and food additives by the intestinal mictoflora represents an important step whether these compounds reach the gut directly after oral ingestion or through the bile after parenteral dosing. The factors which might influence this pathway of metabolism are summarized in Table 2 but in general it most important for polar compounds which are not well absorbed from the gut ar for those compounds which are excreted, free or conjugated, in the bile.

Table 2. Factors affecting intestinal metabolism of anutrients

I. Nature of anutrient
(a) Polarity
(b) Formulation and dose
(c) Structure and stability

2. Nature of exposure
(a) Time and method of administration
(b) Chronic dosing and adaptation

3. Nature of animal

(a) Species differences in structure of the gastro-intestinal tract

(b) Gut motility

(c) Pathological conditions (enteropathies, diarrhoea)

4. Nature and distribution of gut flora
(a) Influence of diet
(b) Exposure to infection (germ-free, specific pathogen-free)
(c) Modification by drugs
(d) Coprophagy

\section{REFERENCES}

Adamson, R. H., Bridges, J. W., Evans, M. E. \& Williams, R. T. (1970). Biochem. F. rr6, 437.

Clark, A. G., Fischer, L. J., Millburn, P., Smith, R. L. \& Williams, R. T. (1968). Biochem. F. 112, i7P.

Dickenson, A. B., Gustafsson, B. E. \& Norman, A. (197r). Acta path. microbiol. scand. Sect. B. 7r, $69 \mathrm{x}$.

Drasar, B. S., Hill, M. J. \& Williams, R. E. O. (1970). In Metabolic Aspects of Food Safety p. 245

[F. J. C. Roe, editor]. Oxford: Blackwell Scientific Publications.

Drasar, B. S., Renwick, A. G. \& Williams, R. T. (1971). Biochem. F. 123, 26 P.

Fore, H., Walker, R. \& Golberg, L. (1967). Fd Cosmet. Toxic. 5, 459.

Gingell, R., Bridges, J. W. \& Williams, R. T. (1969). Biochem. F. I14, 5 P.

Grantham, P. H., Horton, R. E., Weisburger, E. K. \& Weisburger, J. H. (1970). Biochem. Pharmac. 19, 163.

Grasso, P., Gaunt, I. F., Hall, D. E., Golberg, L. \& Batstone, E. (1968). Fd Cosmet. Toxic. 6, I.

Gustafsson, B. E. (1967). In Nutrition \& Infection, Ciba Foundation Study Group No. 3 I [G. E. W. Wolstenholme and M. O'Connor, editors]. London: J. \& A. Churchill.

Hawksworth, G. \& Hill, M. J. (I97I). Biochem. F. I22, $28 P$. 
Kirby, A. H. M. (1945). Biochem. F. 39, xxxiii.

Kojima, S. \& Ichibagase, H. (1966). Cherm. pham. Bull., Tokyo 14, 971.

Leahy, J. S., Wakefield, M. \& Taylor, T. (1967a). Fd Cosmet. Toxic. 5, 447.

Leahy, J. S., Wakefield, M. \& Taylor, T. (1967b). Fd Cosmet Toxic. 5, 595.

Miller, J. A. \& Miller, E. C. (1953). Ad. Cancer Res. ז, 339.

Miller, J. A. \& Milier, E. C. (1967). Carcinogenesis : a Broad Critique p. 397. Baltimore: Willians \& Wilkins.

Murrells, D. F. (1969). The reduction of food azo dyes by rat caecal microflora. PhD Thesis, University of Reading.

Renwick, A. G. \& Williams, R. T. (1969). Biochem. F. 114, 78 P.

Scheline, R. R. (1968a). F. pharm. Sci. 57, 202 I.

Scheline, R. R. (1968b). Acta pharmac. tox. 26, 193.

Scheline, R. R. (197I). Proc. Eur. Soc. Study of Drug Toxicity. ICS no. 254, Vol. 13, p. 35. Amsterdam: Excerpta Medica.

Scheline, R. R. (1972). Xenobiotica 2, 227.

Spatz, M., Smith, D. W. E., McDaniel, E. G. \& Laqueur, G. L. (1967). Proc. Soc. exp. Biol. Med. $\mathbf{x 2 4}, 69 \mathrm{I}$.

Walker, R., Grasso, P. \& Gaunt, I. F. (1970). Fd Cosmet. Toxic. 8, 539.

Williams, J. R. Jr, Grantham, P. H., Yamamoto, R. S. \& Weisburger, J. H. (1970). Biochem. Pharmac. I9, 2523 .

Williams, R. T. (1970). In Metabolic Aspects of Food Safety p. 255 [F. J. C. Roe, editor]. Oxford: Blackwell Scientific Publications.

Williams, R. T., Millburn, P. \& Smith, R. L. (1965). Ann. N.Y.Acad. Sci. 123, 110. 